\title{
Treatment of Right Colonic Diverticulitis: The Role of Nonoperative Treatment
}

\author{
Ma Ru Kim, Bong-Hyeon Kye, Hyung Jin Kim, Hyeon-Min Cho, Seong Taek Oh${ }^{1}$, Jun-Gi Kim ${ }^{1}$ \\ Department of Surgery, St. Vincent Hospital and ${ }^{1}$ Seoul St. Mary's Hospital, The Catholic University of Korea School of Medicine, Seoul, Korea
}

Purpose: The purpose of this study is to evaluate the value of nonoperative treatment for right-sided colonic diverticulitis. Methods: One hundred fifty-eight patients with right-sided colonic diverticulitis were evaluated. Clinical history, physical and radiologic findings, and treatments were reviewed retrospectively. Also, additional episodes and treatment modalities were checked.

Results: Our patients were classified according to treatment modality; 135 patients (85.4\%) underwent conservative treatment, including antibiotics and bowel rest, and 23 patients (14.6\%) underwent surgery. The mean follow-up length was 37.3 months, and 17 patients (17.5\%) underwent recurrent right-sided colonic diverticulitis. Based on treatment modality, including surgery and antibiotics, no significant differences in the clinical features and the recurrence rates were noted between the two groups.

Conclusion: Conservative management with bowel rest and antibiotics could be considered as a safe and effective option for treating right-sided colonic diverticulitis. This treatment option for right-sided colonic diverticulitis, even if the disease is complicated, may be the treatment of choice.

Keywords: Diverticulitis; Colonic diverticulitis; Drug therapy

\section{INTRODUCTION}

Right sided colonic diverticular diseases are detected more frequently in Asians than Caucasians, and it accounts for approximately $55-70 \%$ diverticular diseases in the entire Asian population [1]. In contrast, it has been shown that in Caucasians, diverticular diseases are developed in the left sided colon in most cases, and studies on diverticulitis are also on diverticulitis of left sided colon, and thus studies on the diagnosis or treatment of right sided colonic diverticular diseases that are prevalent in Asians are not sufficient $[2,3]$.

It has been shown that diverticulum in the right sided colon

Received: August 31, 2010 Accepted: October 26, 2010

Correspondence to: Hyeon-Min Cho, M.D.

Department of Surgery, St. Vincent Hospital, The Catholic University of

Korea School of Medicine, 93-6 Ji-dong, Paldal-gu, Suwon 442-723, Korea

Tel: +82-31-249-7084, Fax: +82-31-247-5347

E-mail: hmcho@catholic.ac.kr

(c) 2010 The Korean Society of Coloproctology

This is an open-access article distributed under the terms of the Creative Commons Attribution NonCommercial License (http://creativecommons.org/licenses/by-nc/3.0) which permits unrestricted non-

commercial use, distribution, and reproduction in any medium, provided the original work is properly cited. is the true diverticulum in most cases, it occurs prevalently in relatively young age groups, and with aging, the incidence is not increased [4]. Depending on the condition of patients and depending on medical teams, diverse treatments for right colonic diverticulitis from conservative treatments using medication such as antibiotics to diverticulectomy and right hemicolectomy have been performed. In the past, right sided colonic diverticulitis was misdiagnosed as acute appendicitis and detected incidentally during surgery in many cases $[2,5,6]$. Nonetheless, thanks to the development of computed tomography (CT) and other imaging techniques, right sided colonic diverticulitis could be diagnosed by non-invasive test, and thus for cases diagnosed as right sided colonic diverticulitis, the decision whether to perform surgical treatments or to perform conservative treatments became an important task. Therefore, we examined the role of conservative treatments by analyzing the clinical course of right colonic diverticulitis.

\section{METHODS}

The study was conducted on 158 patients diagnosed as having right-sided colonic diverticulitis from January 2002 to Decem- 
ber 2008. Cases showing diverticulitis findings by CT or barium enema, cases diagnosed as diverticulitis during surgery, and patients with a past history of diverticulitis admitted for identical symptoms were diagnosed as having diverticulitis. The right-sided colon was defined as the area from the appendix to the hepatic flexure. The medical records of these 158 patients were analyzed retrospectively, and gender, age, treatment method, duration of symptoms prior to treatment, frequency of diverticulitis symptoms, body temperature at the time of admission, number of leucocytes at the time of admission, severity of diverticulitis, hospitalization period, fasting period after admission, recurrence of symptoms after discharge, etc. were examined. A body temperature higher than $38^{\circ} \mathrm{C}$ at the time of admission was defined as fever, and leucocytes higher than 10,000/ $\mathrm{m}^{3}$ were classified as leucocytosis. Cases with severe inflammation in the vicinity of the colon and cases in which a pericolic abscess had been detected were classified as complicated diverticulitis (Fig. 1). As the follow-up observation of patients by medical records and telephone, whether diverticulitis symptoms recurred after discharge and whether the patient received surgery were assessed.

As statistical analysis methods, by chi-square test and Fisher's exact test, the differences between factors affecting the clinical features were analyzed. For a comparison of the averages of the subject groups, the Student's t-test was applied. Cases with $\mathrm{P}<$ 0.05 were defined as being statistically significant.

\section{RESULTS}

Among the 158 right colonic diverticulitis patients, males accounted for was 99 patients $(62.7 \%)$, and females accounted for 59 patients $(37.3 \%)$. The mean age was $40.4 \pm 12.0$ years, and 68 patients $(43 \%)$ were older than 40 years. The period from the onset of symptoms to admission was approximately $2.7 \pm$

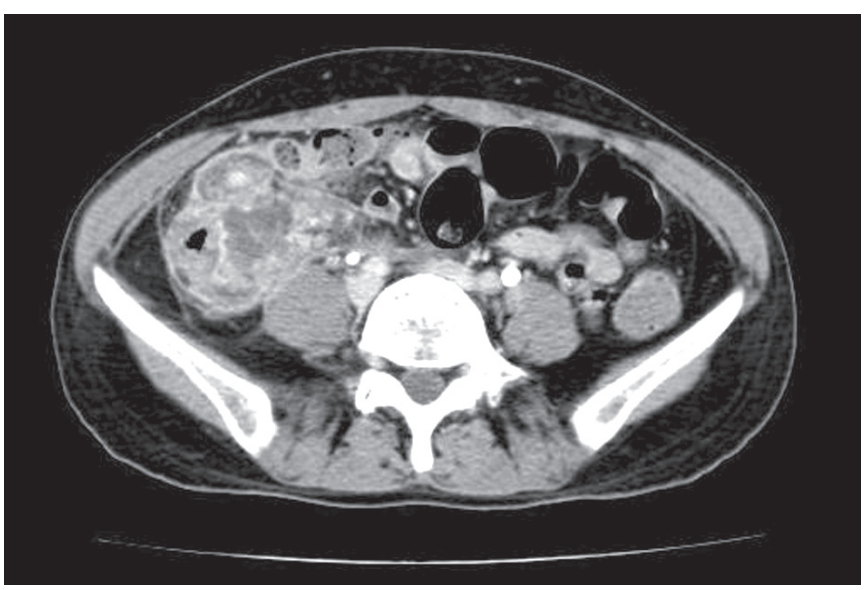

Fig. 1. CT shows complicated diverticulitis on the cecum; a $5.6 \times 5.4$ $\mathrm{cm}^{2}$ ill-defined, mass-like heterogeneous contrast-enhancing lesion in the pericecal area.
1.9 days. In the survey of the frequency of onset, cases with one onset were 137 (86.7\%), and it was the most prevalent frequency of onset. Most cases were diagnosed by imaging tests; nonetheless, 11 patients $(6.9 \%)$ were misdiagnosed during emergency surgery as having appendicitis. An appendectomy and diverticulectomy were performed on 10 cases, and 1 case involved an abscess that had already formed, so only abscess drainage was performed. According to treatment modalities, 134 patients $(85.4 \%)$ were treated with conservative management with applied antibiotics, and 23 patients (14.6\%) underwent surgery. For all patients, antibiotics were used for an average $6.1 \pm 2.7$ days, and the hospitalization stay was an average $7.4 \pm 3.7$ days. During the $37.3 \pm 23.3$ months average follow-up period, rightsided colonic diverticulitis recurred in 17 patients (17.5\%).

A comparison of clinical features according to treatment me-

Table 1. Comparison of clinical features between the two groups divided by treatment modality

\begin{tabular}{|c|c|c|c|}
\hline & $\begin{array}{l}\text { Surgery } \\
(n=23)\end{array}$ & $\begin{array}{l}\text { Conservative } \\
(\mathrm{n}=135)\end{array}$ & $\begin{array}{c}\mathrm{P}- \\
\text { value }\end{array}$ \\
\hline $\begin{array}{l}\text { Sex } \\
\text { Male } \\
\text { Female }\end{array}$ & $\begin{array}{r}14(60.9) \\
9(39.1)\end{array}$ & $\begin{array}{l}85(63.0) \\
50(37.0)\end{array}$ & 0.848 \\
\hline $\begin{array}{l}\text { Age (yr) } \\
\leq 40 \\
>40\end{array}$ & $\begin{array}{r}16(69.6) \\
7(30.4)\end{array}$ & $\begin{array}{l}74(54.8) \\
61(45.2)\end{array}$ & 0.255 \\
\hline $\begin{array}{c}\text { ASA } \\
\text { I } \\
\| \\
\text { III }\end{array}$ & $\begin{array}{c}37.6 \pm 10.85 \\
20(87.0) \\
3(13.0) \\
0(0)\end{array}$ & $\begin{array}{c}40.5 \pm 12.2 \\
106(78.5) \\
25(18.5) \\
4(3.0)\end{array}$ & $\begin{array}{l}0.288 \\
0.290\end{array}$ \\
\hline Symptom duration (day) & $2.6 \pm 1.4$ & $2.8 \pm 2.0$ & 0.724 \\
\hline $\begin{array}{l}\text { No. of previous episodes } \\
\text { Null } \\
\text { More than one }\end{array}$ & $\begin{array}{r}20(87.0) \\
3(13.0)\end{array}$ & $\begin{array}{r}117(86.7) \\
18(13.3)\end{array}$ & 0.970 \\
\hline $\begin{array}{l}\text { Body temperature }\left({ }^{\circ} \mathrm{C}\right) \\
\quad<38.0 \\
\geq 38.0\end{array}$ & $\begin{array}{c}23(100) \\
0(0)\end{array}$ & $\begin{array}{r}121(89.6) \\
14(10.4)\end{array}$ & 0.225 \\
\hline $\begin{array}{l}\text { WBC } \\
\qquad 10,000 / \mathrm{m}^{3} \\
\geq 10,000 / \mathrm{m}^{3}\end{array}$ & $\begin{array}{r}14(60.9) \\
9(39.1)\end{array}$ & $\begin{array}{l}45(33.3) \\
90(66.7)\end{array}$ & 0.018 \\
\hline $\begin{array}{l}\text { Severity } \\
\text { Uncomplicated } \\
\text { Complicated }\end{array}$ & $\begin{array}{r}19(82.6) \\
4(17.4)\end{array}$ & $\begin{array}{c}124(91.9) \\
11(8.1)\end{array}$ & 0.238 \\
\hline Duration of antibiotic use (day) & $5.6 \pm 1.8$ & $6.1 \pm 2.8$ & \\
\hline Duration of NPO (day) & $3.5 \pm 1.4$ & $3.9 \pm 2.0$ & \\
\hline Hospital stay (day) & $7.8 \pm 2.4$ & $7.6 \pm 3.9$ & \\
\hline Length of follow-up (mo) & $56.5 \pm 17.8$ & $34.3 \pm 22.7$ & \\
\hline $\begin{array}{l}\text { Recurrent attack after discharg } \\
\text { No } \\
\text { More than one }\end{array}$ & $\begin{array}{l}=97) \\
11(84.6) \\
2(15.4)\end{array}$ & $\begin{array}{l}69 \text { (82.1) } \\
15(17.9)\end{array}$ & 0.828 \\
\hline
\end{tabular}

Values are presented as mean \pm SD or number (\%).

SD, standard diviation; ASA, American Society of Anesthesiologist; NPO, nil per os. 
thods is shown in Table 1. Leucocytosis was observed abundantly in the group treated with antibiotics $(P=0.018)$. Other than that, no differences in clinical features were detected. Furthermore, longer follow-ups were performed for patients who underwent surgery $(\mathrm{P}=0.001)$. Recurrence of diverticulitis in the two groups during the follow-up period was 2 cases in the group that underwent surgery (15.4\%) and 15 cases in the group that underwent conservative treatments $(17.9 \%)$, but the difference was not statistically significant $(\mathrm{P}=0.828)$.

During the follow-up period after discharge, the status of recurrence could be assessed in 97 patients (61.1\%). Among them, recurrence could be confirmed in 17 cases. Among those 17 cases, 2 were patients who underwent an appendectomy and diverticulectomy simultaneously at the time of admission, and 5 , including the 2 that underwent surgery at the time of first admission, were patients who underwent a right hemicolectomy. The remaining 12 patients were subjected to antibiotic treatment. Among patients available for follow-up observation, none developed diseases in the colon other than diverticular diseases. When the effect of the clinical features of the first inpatient treatment period on recurrence was examined, except for the high frequency of recurrence in the group of patients

Table 2. Comparison of clinical features at the time of initial admission between the two groups divided by whether recurrent right-sided colonic diverticulitis developed or not

\begin{tabular}{|c|c|c|c|}
\hline & No $(n=80)$ & Yes $(n=17)$ & P-value \\
\hline $\begin{array}{l}\text { Sex } \\
\text { Male } \\
\text { Female }\end{array}$ & $\begin{array}{l}53(66.3) \\
27(33.8)\end{array}$ & $\begin{array}{r}12(70.6) \\
5(29.4)\end{array}$ & 0.731 \\
\hline $\begin{array}{l}\text { Age (yr) } \\
\leq 40 \\
>40\end{array}$ & $\begin{array}{l}47(58.8) \\
33(41.3)\end{array}$ & $\begin{array}{r}5(29.4) \\
12(70.6)\end{array}$ & 0.034 \\
\hline $\begin{array}{l}\text { ASA } \\
\text { I } \\
\| \\
\text { III }\end{array}$ & $\begin{array}{c}39.9 \pm 12.6 \\
59(73.8) \\
18(22.5) \\
3(3.8)\end{array}$ & $\begin{array}{c}44.3 \pm 13.7 \\
16(94.1) \\
1(5.9) \\
0(0)\end{array}$ & $\begin{array}{l}0.196 \\
0.074\end{array}$ \\
\hline Symptom duration (day) & $2.7 \pm 1.8$ & $2.8 \pm 1.7$ & 0.909 \\
\hline $\begin{array}{l}\text { No. of previous episodes } \\
\text { Null } \\
\text { More than one }\end{array}$ & $\begin{array}{r}72(90.0) \\
8(10.0)\end{array}$ & $\begin{array}{c}16(94.1) \\
1(5.9)\end{array}$ & 0.597 \\
\hline $\begin{array}{l}\text { Severity } \\
\text { Uncomplicated } \\
\text { Complicated }\end{array}$ & $\begin{array}{r}72(90.0) \\
8(10.0)\end{array}$ & $\begin{array}{c}17(100) \\
0(0)\end{array}$ & 0.344 \\
\hline $\begin{array}{l}\text { Initial treatment } \\
\text { Surgery } \\
\text { Antibiotics }\end{array}$ & $\begin{array}{l}11(13.8) \\
69(86.2)\end{array}$ & $\begin{array}{r}2(11.8) \\
15(88.2)\end{array}$ & 0.828 \\
\hline Duration of antibiotic use (day) & $5.8 \pm 23.2$ & $7.8 \pm 4.7$ & 0.112 \\
\hline Duration of NPO (day) & $3.9 \pm 1.9$ & $4.4 \pm 2.9$ & 0.433 \\
\hline Hospital stay (day) & $7.3 \pm 3.1$ & $7.3 \pm 2.9$ & 0.994 \\
\hline
\end{tabular}

Values are presented as mean \pm SD or number (\%).

SD, standard diviation; ASA, American Society of Anesthesiologist; NPO, nil per os. than 40 years $(P=0.034)$, no other factors were statistically significant (Table 2).

\section{DISCUSSION}

Right-sided colonic diverticulitis is a disease whose incidence is on the rise with increasing diverticular diseases as diets have become more westernized, and tests and diagnosis methods have been reported [7]. Different from western countries, in Asia, including Korea, primarily right-sided colonic diverticulitis has been reported, and it occurs primarily in the cecum [8, 9]. With the increase in right-sided colonic diverticulum, the frequency of right colonic diverticulitis has also increased, and studies on the adequacy of the application of treatments for left colonic diverticulitis developed in the West have been published [5-9]. In regard to cases with left colonic diverticulitis, particularly sigmoid colonic diverticulitis, surgical treatments are recommended for young patients and for patients in whom diverticulitis symptoms have developed more than 2 times [10]. Nevertheless, the characteristics that right sided colonic diverticulitis is a solitary occurrence in $80 \%$ of the cases is different from left colonic diverticulitis. Many cases are the true diverticulum, and the incidence does not increase with aging [4]. In the past, right-sided colonic diverticulitis was misdiagnosed as acute appendicitis in many cases. Nevertheless, recently, it has been diagnosed accurately by using CT [1-3, 5-9, 11-18].

Many studies have reported that conservative treatments including antibiotic treatments for right-sided colonic diverticulitis have shown good treatment outcomes, so conservative treatments administering antibiotics rather than performing surgery are recommended. Although it varies depending on the investigator, the recurrence rate after conservative treatments is shown to be approximately $3-15 \%[6-8,11,12]$. The results of our study show that the hospitalization period of patients receiving surgical treatments was an average $7.8 \pm 2.4$ days, which was not statistically different from the $7.4 \pm 3.9$ days for patients treated with antibiotics only $(\mathrm{P}=0.571)$. Also, the fasting periods $(3.5 \pm 1.4$ days vs. $3.9 \pm 2.0$ days, $\mathrm{P}=0.387)$ and the durations of antibiotic treatments $(5.6 \pm 1.8$ days vs. $6.1 \pm 2.8$ days, $\mathrm{P}=0.403$ ) of the group that underwent surgery and the group treated with antibiotics only were not statistically different. The recurrences after treatment for the two groups did not show statistical differences $(\mathrm{P}=0.828)$. Thus, based on these results, in cases diagnosed as right-sided colonic diverticulitis, treatment outcomes of surgical treatments and conservative treatments, including antibiotic treatments, are comparable. Hence, for cases diagnosed as having right colonic diverticulitis, performing conservative treatments and observing the clinical course of the patients, rather than performing surgery, could reduce unnecessary surgery.

In addition, numerous investigators have reported that even for cases with recurred right-sided colonic diverticulitis, the 
response to conservative treatments, including antibiotic treatments, is good, and the recurrence rate is low; thus, for the treatment of recurrent right-sided colonic diverticulitis, non-surgical treatments are also recommended $[6,11,12]$. In our study, in 97 patients who were available for the follow-up observation, recurrence in 17 patients (17.5\%) was observed. Their clinical characteristics at the first admission were compared. Besides the higher recurrence rate in patients older than 40 years, no other significant findings were detected. Particularly, the recurrence rate of the group that underwent surgical treatments was found to be comparable to the group that underwent conservative managements ( $15 \%$ vs. $17 \%, \mathrm{P}=0.828$ ). Even in cases with a history of diverticulitis prior to admission, the recurrence rate was not high $(11.1 \%)$. This may allow the application of surgical indications developed based on left-sided colonic diverticulitis to be applied to right colonic diverticulitis. However, until now, treatments for right-sided colonic diverticulitis associated with an abscess and other complications have not been established, and studies are not abundant. In addition, studies showing that diverticulitis could be treated with conservative treatments without surgery are limited to simple diverticulitis without associated complications in most cases $[3,6,17,19]$. Recently, results for conservative treatments for complicated diverticulitis associated with complications have been reported in several reports. Tonelli et al. [20] have reported that a pericolic abscess smaller than $5 \mathrm{~cm}$ could be treated without surgery. Moon et al. [12] have reported that 62 right colonic diverticulitis patients were examined, and 7 patients (11.3\%) were found to have associated complications, all pericolic abscesses. Our study included 15 cases (9.5\%) of complicated diverticulitis, and all complications were pericolic abscesses, Hinchey I. Among those 15 cases, 4 (26.7\%) underwent surgery. The proportion of patients undergoing surgery for complicated diverticulitis was high, but when it was compared with that of patients undergoing surgery for simple diverticulitis, the difference was not statistically significant $(\mathrm{P}=0.238)$.

For patients with complicated diverticulitis who underwent surgery, the surgery was performed because the condition had been diagnosed by imaging tests prior to surgery. In addition, in most cases, efforts were made to remove all the area with lesions by performing radical surgery. Nevertheless, one patient with the complication of a severe pericolic abscess was treated with both an appendectomy and drainage of the abscess. Thus, for the treatment of complicated diverticulitis, considering not only radical surgery as the treatment method, but also attempting conservative treatment with antibiotics, ultrasound guide percutaneous drainage, or drainage through surgery first is thought to be better. Only if such treatments fail should radical surgery be considered.

Our study has limitations in that it was a retrospective study using the medical records of patients, and the follow-up observation could not be performed on all patients. In the future, for the natural course of right colonic diverticulitis and for the preparation of treatment guidelines, such as treatment principles, etc., random prospective studies are thought to be required. In addition, a concept of right colonic diverticulitis needs to be established in a manner similar to that used to establish the concept of left colonic diverticulitis in the West. Most cases of right colonic diverticulitis are cases of simple diverticulitis, and for such cases, conservative treatments are thought to be better. Even in cases of complicated diverticulitis with associated complications, most cases are pericolic abscesses, hence, surgery should not be considered in the beginning; rather, conservative treatments should be performed first, the clinical course should be observed, and then the decision whether to perform surgery should be made.

\section{CONFLICT OF INTEREST}

No potential conflict of interest relevant to this article was reported.

\section{REFERENCES}

1. Lee IK, Kim SH, Lee YS, Kim HJ, Lee SK, Kang WK, et al. Diverticulitis of the right colon: tips for preoperative diagnosis and treatment strategy. J Korean Soc Coloproctol 2007;23:223-31.

2. Lo CY, Chu KW. Acute diverticulitis of the right colon. Am J Surg 1996;171:244-6.

3. Komuta K, Yamanaka S, Okada K, Kamohara Y, Ueda T, Makimoto $\mathrm{N}$, et al. Toward therapeutic guidelines for patients with acute right colonic diverticulitis. Am J Surg 2004;187:233-7.

4. Park JK, Sung JK, Choi SH, Yun SS, Lee S. Clinical analysis of right colon diverticulitis. J Korean Surg Soc 2003;64:44-8.

5. Lane JS, Sarkar R, Schmit PJ, Chandler CF, Thompson JE Jr. Surgical approach to cecal diverticulitis. J Am Coll Surg 1999;188: 629-34.

6. Yang HR, Huang HH, Wang YC, Hsieh CH, Chung PK, Jeng LB, et al. Management of right colon diverticulitis: a 10-year experience. World J Surg 2006;30:1929-34.

7. Kim KY, Kim IK, Jung SW, Park KH, Park YJ. Analysis on the surgical treatment of colonic diverticulitis. J Korean Surg Soc 2007;73:36-41.

8. Oh JP, Kim BG. Cecal Diverticulitis and its managements. J Korean Surg Soc 1997;53:243-51.

9. Cho HJ, Cho SY, Oh JH. Clinical analysis of right colonic diverticulitis that was operated under the impression of acute appendicitis. J Korean Soc Coloproctol 2000;16:18-24.

10. Janes S, Meagher A, Faragher IG, Shedda S, Frizelle FA. The place of elective surgery following acute diverticulitis in young patients: when is surgery indicated? An analysis of the literature. Dis Colon Rectum 2009;52:1008-16.

11. Park HC, Chang MY, Lee BH. Nonoperative management of right colonic diverticulitis using radiologic evaluation. Colorectal Dis 


\section{Coloproctology Ma Ru Kim, et al.}

2010;12:105-8.

12. Moon HJ, Park JK, Lee JI, Lee JH, Shin HJ, Kim WS, et al. Conservative treatment for patients with acute right colonic diverticulitis. Am Surg 2007;73:1237-41.

13. Kang JY, Melville D, Maxwell JD. Epidemiology and management of diverticular disease of the colon. Drugs Aging 2004;21:211-28.

14. Shyung LR, Lin SC, Shih SC, Kao CR, Chou SY. Decision making in right-sided diverticulitis. World J Gastroenterol 2003;9:606-8.

15. Fang JF, Chen RJ, Lin BC, Hsu YB, Kao JL, Chen MF. Aggressive resection is indicated for cecal diverticulitis. Am J Surg 2003;185: $135-40$.

16. Kirkwood KS, Maa J. The appendix. In: Sabiston DC, Townsend CM. Sabiston textbook of surgery: the biological basis of modern surgical practice. 18th ed. Philadelphia: Saunders/Elsevier; 2008. p. 1333-47.

17. Matsushima K. Management of right-sided diverticulitis: a retrospective review from a hospital in Japan. Surg Today 2010;40: 321-5.

18. Yang SC, Lee KP, Shon SK, Kim MW, Min JS. Clinical analysis of colonic diverticular disease in Koreans. Korean J Gastroenterol 1987;19:485-90.

19. Park SJ, Choi SI, Lee SH, Lee KY. Image-guided conservative management of right colonic diverticulitis. World J Gastroenterol 2009;15:5838-42.

20. Tonelli F, Di Carlo V, Liscia G, Serventi A. Diverticular disease of the colon: diagnosis and treatment. Consensus Conference, 5th National Congress of the Italian Society of Academic Surgeons. Ann Ital Chir 2009;80:3-8. 